\title{
Generational increase of self-reported first attack of asthma in fifteen industrialized countries
}

\author{
J. Sunyer*, J.M. Antó*, A. Tobias*, P. Burney ${ }^{+}$, for the European Community \\ Respiratory Health Study (ECRHS)
}

\begin{abstract}
Generational increase of self-reported first attack of asthma in fifteen industrialized countries. J. Sunyer, J.M Antó, A. Tobias, P. Burney, for the European Community Respiratory Health Study (ECRHS). C ERS Journals Ltd 1999.

ABSTRACT: The prevalence of asthma has increased worldwide. However, there is only local evidence for changes in incidence. Data from the European Community Respiratory Heath Survey (ECRHS) can be analysed to reconstruct trends in incidence from 1946-1991 in cohorts born between 1946-1971 in 35 areas corresponding to 15 countries. The authors report the time trends in self-reported first occurrence of asthma and its geographical distribution.

All centres completed the same cross-sectional study in 1991-92. A total of 17,613 individuals $(63 \%$ of those randomly selected) were included. Recall of age of first asthma attack was recorded at an interview at one point in time in subjects aged 20-44 yrs. Relative risk of asthma by cohort was estimated using survival methods with age as the time scale.

Yearly incidence of asthma increased progressively by birth cohort. The relative risks were $1.12(0.94-1.34), 1.39(1.17-1.66), 2.01(1.60-2.51)$, and $2.33(1.81-2.98)$ for the cohorts born in the years 1951-55, 1956-60, 1961-65, and 1966-71, respectively, in comparison with the cohort born in the years 1946-50. The increase occurred concurrently in most of the countries, in both males and females, and both in childhood and adulthood onset asthma.

These results are consistent with a generational increase in asthma incidence during the previous decades (explained by both a period and/or a cohort effect), although some of the findings could be explained by generational increases in asthma diagnosis. Eur Respir J 1999; 14: 885-891.
\end{abstract}

*Unitat de Recerca Respiratòria i Ambiental. Institut Municipal Investigació Mèdica (IMIM), Barcelona, Catalonia, Spain, 'Dept of Public Health Medicine, United Medical and Dental Schools of Guy's and St. Thomas's Hospitals, London, UK.

\section{Correspondence: J. Sunyer}

Unitat de Recerca Respiratòria i Ambiental

Institut Municipal d'Investigació Mèdica (IMIM)

Doctor Aiguader 80

E-08003 Barcelona

Spain

Fax 34932213237

\section{Keywords: Asthma}

cohort

incidence

self-reported first occurrence

Received: October 61998

Accepted after revision May 231999

The aetiology of asthma remains largely obscure. Its worldwide increasing trend has been the subject of persistent attention with the hope of identifying the causative environmental factors, and if possible of preventing them. A shift in time trends of asthma was noticed as a result of sudden changes in mortality reported in the United Kingdom in the 1960s [1], though asthma mortality in 5-24 yr olds had been rising slowly but steadily since the beginning of the century [2]. A further increase in mortality was reported in the mid 1970s in several countries [3-6]. These changes could have been explained either by changes in case fatality or by changes in the prevalence or severity of disease, or by changes in labelling, or by changes in the way that death certificates were completed or coded. A concurrent increase in hospital admissions was also reported in many different countries [7-8], and this could also be explained in many different ways, with the added possibility that hospitalization rates are strongly influenced by changes in current medical practice. However, there was a cohort effect in both the mortality and admissions data, which cannot be explained by a change in coding [9].

Evidence of a generalized increase in asthma prevalence (from $5 \%$ to $10 \%$ per year from the end of the 1960 s) was reported in the 1970s [10] and extensively in the late 1980 s and early 1990s based on repeated surveys of asthma conducted in many different countries [7]. Difficulties encountered in interpreting many of these studies include poor standardization of methods and the estimation of trends from only two observations. However there is collateral evidence to suggest that there had also been an increased prevalence of both sensitization and other atopic disease [7]. Prevalence rates result from both incidence rates and duration (balance between relapse and remission) of the disease, and repeat surveys cannot assess time trends in incidence. A longitudinal study in Rochester (MN, USA) found an increase in incidence rates, and no changes in remission rates [11], but more international information is lacking.

The European Community Respiratory Health Survey (ECRHS), an international cross-sectional study on asthma prevalence and risk factors conducted in 1991 and 1992, identified subjects who were currently, or had ever been, asthmatics among a random population sample of subjects born between 1946-1971, and asked about age of onset of asthma [12]. This information can be used to estimate trends in incidence from 1946-1991 in cohorts born between 1946-1971 for 35 areas in 15 countries. The present paper assesses time trends in self-reported first attack of asthma and its geographical distribution.

\section{Methods}

The protocol for the ECRHS has been described elsewhere $[12,13]$. Briefly, participating centres selected an area defined by pre-existing administrative boundaries, 
with a population of at least 150,000 individuals. An upto-date sampling frame was used to randomly select at least 1,500 males and 1,500 females, aged 20- yrs. In stage I, subjects were sent a questionnaire enquiring about respiratory symptoms. A 20\% random sample of subjects was selected to take part in stage II in which they were invited to answer a more detailed administered questionnaire, and to take part in blood tests, skin tests, assessment of lung function by spirometry and airway challenge with methacholine. The present study included subjects randomly selected in stage II. Of 43 participating centres, data was included from 35 centres in 15 countries. The remaining centres had not fully checked and edited their data. Response to stage II varied from $20 \%$ in France to $89 \%$ in Sweden (table 1). The overall response rate was $63 \%$.

Subjects of different ages were interviewed at one point in time between the years 1991-1992. Asthma was defined by an affirmative answer to the question "Have you ever had asthma" and age of onset was established using the question "How old were you when you had your first asthma attack", which was confirmed against age and age of the last asthma attack. Using this information the authors measured events (first occurrence of asthma) and not status. Given that incidence focuses on events and prevalence on status, the measure of frequency used in this analysis is incidence of asthma. The incidence of asthma was expressed as the yearly incidence for a given age group, cohort and calendar period. Yearly incidence was estimated by the number of first occurrences of the disease over the sum of times that every person in the population is observed (i.e., total persons-years at risk) based on age. The time contributed by each individual that experiences an asthma attack is limited up until the occurrence of the event, but not afterward. All individuals entered into observation at age zero (i.e., time of birth). To compare incidence between two cohorts the relative risk was calculated using survival methods, assuming that yearly incidence approximates to the risk (or instantaneous hazard) of asthma. The curve of instantaneous hazard of asthma by cohort of birth was estimated by the Kaplan-Meyer method and the ratio of two instantaneous hazards (i.e., relative hazard, or relative risk) was calculated with Cox proportional hazard regression [14], with Stata Statistical Software, release 5.0 (StataCorp; College Station, TX, USA). Since the time scale used was age, the comparison of the risk of asthma was carried out among groups of comparable ages. Quantification of the relative risk of asthma per cohort was carried out for each country. To estimate the joint increase for all countries together, all of the relative hazards of the countries were meta-analysed using a random effects model that allows controlling for heterogeneity among the countries [15]. To adjust for individual variables such as parental asthma (reported by questionnaire), a pooled analysis was also carried out. Relative risks estimated using meta-analysis and pooled analysis were very similar.

\section{Results}

A description of the data by country is shown in table 1 . Yearly incidence of asthma varied notably between countries, Australia and New Zealand having the highest incidences and Spain and Germany the lowest for asthma starting before age 15, and Belgium and the Netherlands the lowest for asthma starting after that age.

Risk of asthma by cohort increased progressively from the baseline cohort of people born in 1946-1950 (fig. 1a), the yearly incidence per 1,000 persons being $1.87,2.10$,

Table 1. - Description by country, yearly incidence of asthma, and prevalence of parental asthma

\begin{tabular}{|c|c|c|c|c|c|c|c|c|}
\hline \multirow[b]{2}{*}{ Country } & \multirow[b]{2}{*}{ Centres } & \multirow[b]{2}{*}{$\begin{array}{l}\text { Participation } \\
\text { rate }\end{array}$} & \multirow[b]{2}{*}{$\mathrm{n}$} & \multirow[b]{2}{*}{$\begin{array}{c}\text { Mean } \\
\text { age }\end{array}$} & \multirow[b]{2}{*}{$\begin{array}{l}\text { Percentage } \\
\text { male }\end{array}$} & \multicolumn{2}{|c|}{$\begin{array}{c}\text { Yearly } \\
\text { incidence } \\
\text { of asthma }\end{array}$} & \multirow{2}{*}{$\begin{array}{l}\text { Prevalence } \\
\text { of parental } \\
\text { asthma }\end{array}$} \\
\hline & & & & & & $0-15$ & $16-44$ & \\
\hline Australia & Melbourne & 41 & 666 & 34.4 & 48.1 & 6.7 & 2.9 & 19.9 \\
\hline Belgium & Antwerp city, Antwerp south & 68 & 1118 & 32.5 & 43.8 & 2.9 & 0.3 & 7.8 \\
\hline \multirow[t]{2}{*}{ France } & Bordeaux, Grenoble, Montpellier, & & & & & & & \\
\hline & Paris & 20 & 2107 & 34.3 & 49.7 & 5.9 & 1.8 & 11.3 \\
\hline Germany & Erfurt, Hamburg & 46 & 1981 & 33.1 & 50.8 & 1.3 & 0.9 & 8.5 \\
\hline Iceland & Reykjavik & 84 & 559 & 32.9 & 48.4 & 1.9 & 1.0 & 12.5 \\
\hline Ireland & Dublin & 76 & 427 & 32.2 & 50.1 & 2.8 & 1.0 & 8.4 \\
\hline Italy & Pavia, Torino, Verona & 49 & 890 & 33.3 & 49.8 & 3.2 & 1.2 & 10.2 \\
\hline Netherlands & Bergen-op-Zoom, Gelen, Groningen & 65 & 1243 & 33.6 & 48.5 & 2.2 & 0.3 & 9.0 \\
\hline \multirow[t]{2}{*}{ New Zealand } & Christchurch, Hawkes-Bay, & & & & & & & \\
\hline & Wellington & 63 & 1236 & 34.0 & 47.0 & 6.3 & 2.0 & 14.7 \\
\hline Norway & Bergen & 87 & 834 & 32.7 & 49.1 & 3.1 & 1.0 & 10.5 \\
\hline Spain & $\begin{array}{l}\text { Albacete, Barcelona, Galdakao, } \\
\text { Huelva, Oviedo }\end{array}$ & 70 & 1940 & 34.3 & 48.2 & 1.5 & 0.5 & 11.1 \\
\hline Sweden & Goteborg, Umea, Uppsala & 89 & 1854 & 32.8 & 48.8 & 3.1 & 1.2 & 14.2 \\
\hline Switzerland & Basel & 72 & 845 & 32.4 & 50.2 & 2.7 & 1.5 & 10.9 \\
\hline \multirow[t]{2}{*}{ UK } & Caerphilly, Cambridge, Ipswich, & & & & & & & \\
\hline & $\begin{array}{l}\text { Norwich } \\
\text { Portland }\end{array}$ & $\begin{array}{l}66 \\
45\end{array}$ & $\begin{array}{r}1532 \\
381\end{array}$ & $\begin{array}{l}33.4 \\
350\end{array}$ & $\begin{array}{l}42.7 \\
457\end{array}$ & $\begin{array}{l}4.1 \\
47\end{array}$ & 1.7 & $\begin{array}{l}12.4 \\
128\end{array}$ \\
\hline Total & & 63 & 17613 & 33.1 & 48.1 & $\begin{array}{l}4.1 \\
3.3\end{array}$ & $\begin{array}{l}2.0 \\
1.2\end{array}$ & $\begin{array}{l}12.8 \\
11.4\end{array}$ \\
\hline
\end{tabular}

Participation rate and prevalence of parental asthma are given as percentages. ${ }^{*}:$ number of subjects included in the present study; ${ }^{\dagger}$ : yearly incidence from $0-15$ yrs of age, and from 16-44 yrs. Age 15 was the median age of asthma onset. Yearly incidence $=($ number of incident cases $/ \Sigma$ person-year) $\times 1000$. 

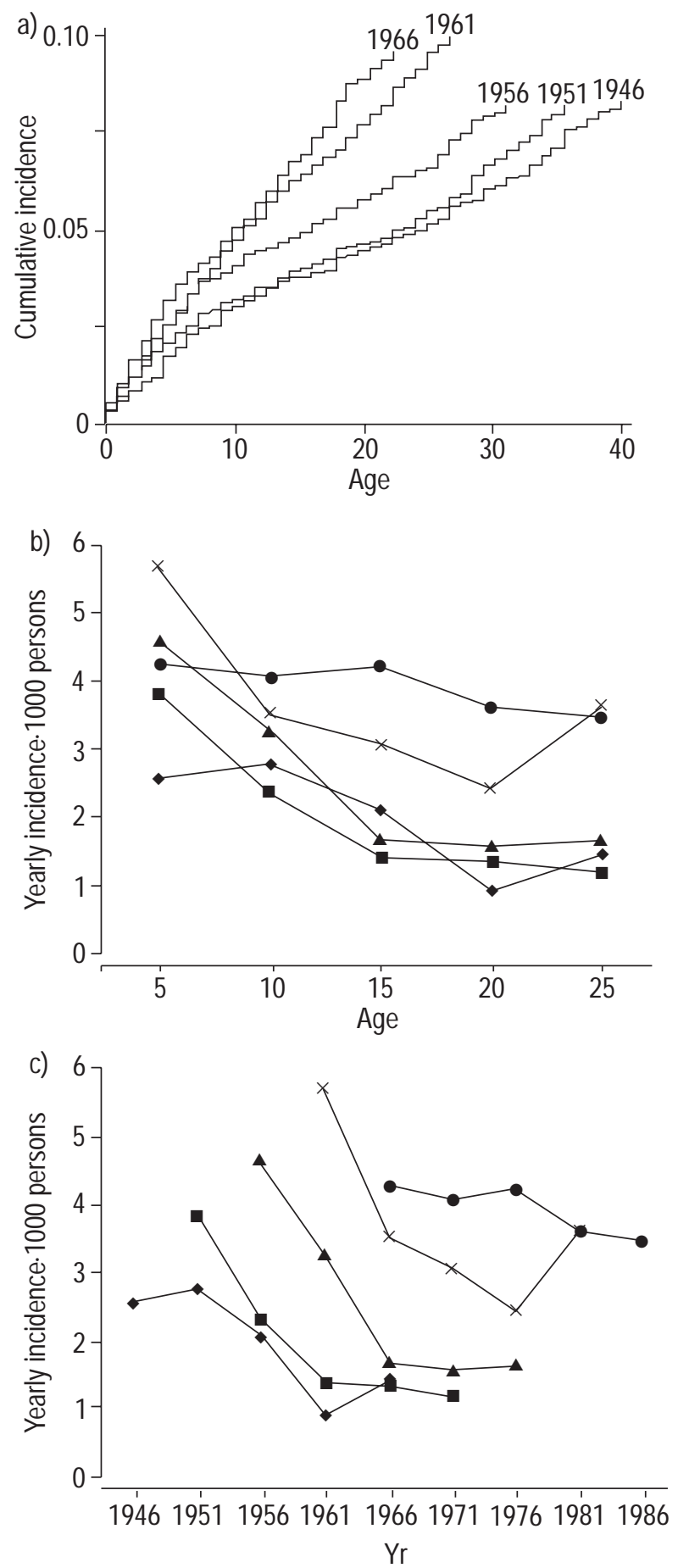

Fig. 1. - Frequency of asthma by birth cohort: a) risk by age; b) yearly incidence by age; c) yearly incidence by calendar year. $\$$ : 1946; 1951; А: 1956; × :1961; ๑: 1966.

$2.37,3.36$, and 3.86 , respectively for each cohort. In the youngest age group, incidence rates increased for the first four cohorts (fig. 1b and 1c). The increase was maintained across the whole range of ages for the cohort born 19611965 , and to a lesser extent for the cohort born in 19561960 (not at 15 yrs of age), and in 1966-1971 (not at 5, and not at 25). Yearly incidence of asthma decreased with age in all birth cohorts (fig. 1b), although the decline with age was attenuated after 1966 (fig. 1c). Age of asthma onset was weakly correlated with age at the time of the study (correlation coefficient $=0.29$ ).

The risk of asthma of the cohort born in 1966 was $>2$ times higher than the risk of the cohort born in 1946 (table $2)$. The increase was statistically significant for the cohorts born in 1956-1960 and later. All cohorts showed a relative increase in comparison to the preceding cohort, but this was only statistically significant for the cohorts born in 1956-1960 and 1961-1965 ( $\mathrm{p}<0.05)$. Adjustment for parental asthma did not confound the secular increase in incidence (e.g., the relative risks for the cohort of 1966-1971 were 2.58 (95\% confidence interval, 1.833.64 ) and 2.31 (1.89-2.83), for those with and without parental asthma, respectively). Males and females showed a very similar increase. Stratified analysis by age groups, adjusting for sex and country, showed that the increase in incidence also occurred in older ages after the cohort born in 1956-1960.

The increase in incidence occurred in most of the countries, except in the Netherlands and Norway (fig. 2). Spain, Switzerland, Sweden, Italy, the United Kingdom, Australia and France showed a statistically significant increase in the cumulative incidence of asthma in the cohort of 1961. All these countries except Italy, in addition to Germany, Iceland and New Zealand showed a statistically significant increase in the cohort of 1966. Belgium and Ireland showed a continuous increase from 1956, though this was not statistically significant. Finally, the Netherlands, Norway and the USA showed little increase in incidence by cohort, although the USA had extremely large confidence intervals for the last cohort, due to the very small sample size. The differences between countries in the increase in asthma incidence were significant for the last two cohorts (heterogeneity $\mathrm{p}<0.1$ ) (fig. 2).

\section{Discussion}

These results provide information of a generational increase of self-reported first occurrence of asthma in populations born after 1945 and covering a wide range of industrialized countries in Europe and other continents. This secular increase has occurred in similar periods in most countries except in the Netherlands, Norway, and the USA.

These results should be interpreted as being consistent with a generalized increase in asthma prevalence during the previous decades and indicate that such an increase has resulted from an increase in incidence rates in the youngest age group, and also from an increase in incidence rates in older ages. However, an alternative explanation that is impossible to rule out, as discussed below, is that some of the findings could be due to secular changes in diagnostic labelling of asthma. The increase of prevalence reported by previous studies $[8,10]$ could also be explained by changes in the duration of the disease. Duration is not well characterized in the study. However, no relation was found between the cohort of birth and an indicator of duration such as severity, since the proportion of subjects reporting $\geq 5$ attacks of asthma during the last 12 months among all subjects reporting asthma did not increase by cohort (being 33, 37, 48, 34 and 39\%, respectively by cohort, adjusting for sex). Other studies have found a lack of increase of asthma severity in England [16] and the USA [17]. 
Table 2. - Relative risk of asthma by cohort of birth

\begin{tabular}{|c|c|c|c|c|c|c|}
\hline \multirow[b]{2}{*}{ Cohort } & \multirow[b]{2}{*}{$\mathrm{n}$} & \multirow{2}{*}{$\begin{array}{c}\text { All } \\
\text { subjects }\end{array}$} & \multicolumn{2}{|c|}{ By sex } & \multicolumn{2}{|c|}{ By age of onset } \\
\hline & & & Males & Females & $0-15$ yrs & $15-45 \mathrm{yrs}$ \\
\hline 1946 & 3671 & 1 & 1 & 1 & 1 & 1 \\
\hline 1951 & 3584 & $1.13(0.96-1.34)$ & $1.16(0.91-1.49)$ & $1.10(0.88-1.38)$ & $1.06(0.83-1.33)$ & $1.22(0.96-1.54)$ \\
\hline 1956 & 3507 & $1.39(1.17-1.66)$ & $1.42(1.10-1.82)$ & $1.38(1.09-1.74)$ & $1.36(1.01-1.70)$ & $1.42(1.10-1.86)$ \\
\hline 1961 & 3631 & $2.01(1.60-2.51)$ & $2.10(1.38-3.02)$ & $1.98(1.57-2.51)$ & $1.78(1.44-2.20)$ & $2.53(1.93-3.32)$ \\
\hline 1966 & 3220 & $2.33(1.81-2.98)$ & $2.32(1.66-3.24)$ & $2.47(1.93-3.18)$ & $1.99(1.61-2.47)$ & $3.51(2.58-4.77)$ \\
\hline
\end{tabular}

*: relative risk and $(95 \%$ confidence interval) adjusted for age, sex and country.

The data come from a cross-sectional study and not from a cohort, something which may bias the relative increases in incidence. The major concern is that cross-sectional studies involve survivor populations. However, a bias in the relative increase of incidence could only have occurred if migration (and to a lesser extent death) was related with the occurrence of a first asthma event differently by age, period or cohort. This is impossible to ascertain retrospectively, but is unlikely to occur in a multicentre study where migration related to asthma would have to occur concurrently in all areas.
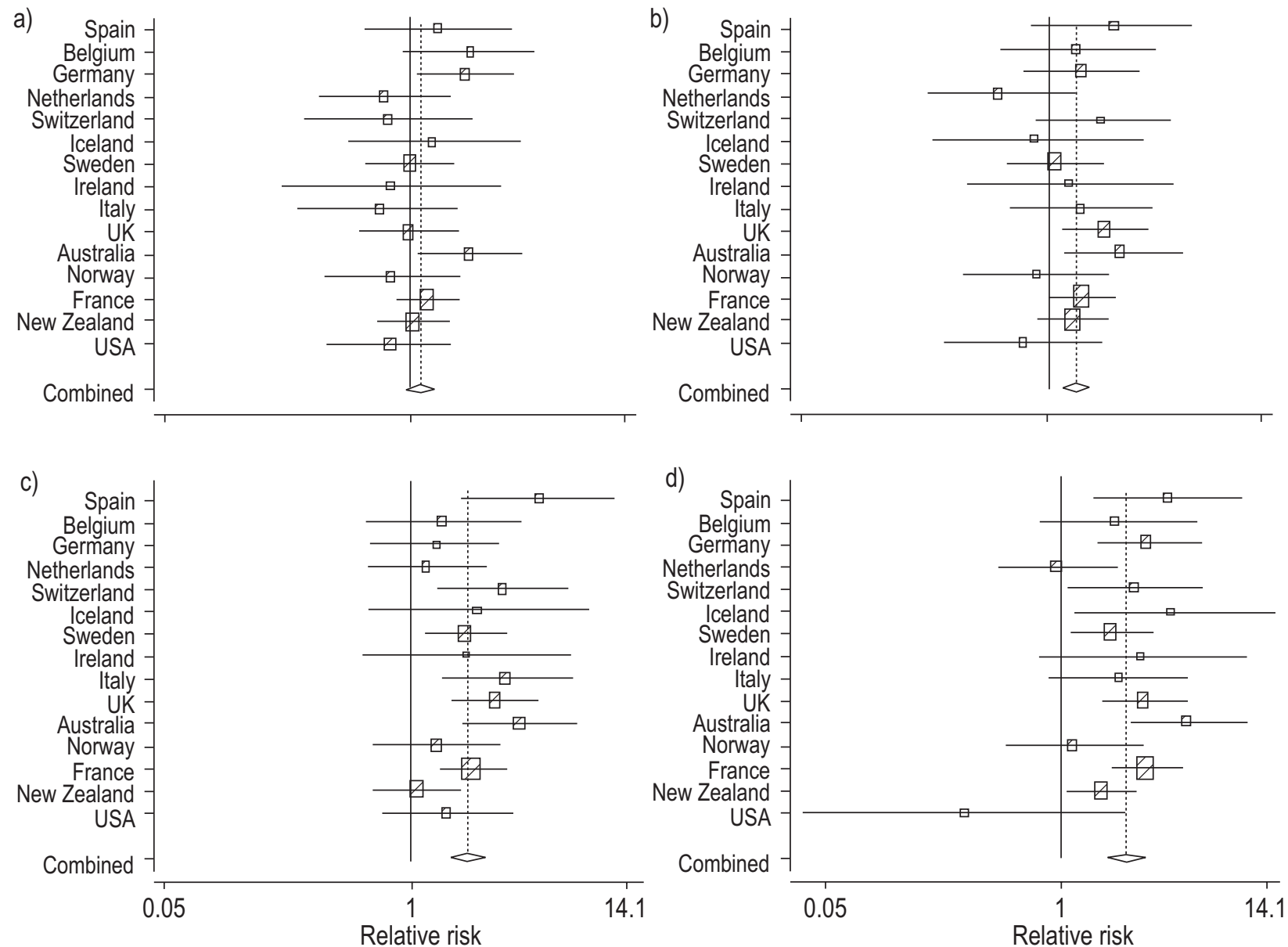

Fig. 2. - Relative risk and 95\% confidence intervals (95\% CI) of asthma by cohort with respect to the basal cohort (i.e., born in 1946-1950) per country, and combined relative risk. a) cohort 1951-1955, b) cohort 1956-1960, c) cohort 1961-1965, d) cohort $\geq 1966$. Countries ordered according to the age and sex adjusted prevalence of asthma in the cohort 1946-1950. Prevalences were 2.2\% Spain, 3.5\% Belgium, 4.6\% Germany, 6.0\% the Netherlands, 6.1\% Switzerland, 7.8\% Iceland, 8.0\% Sweden, 8.2\% Ireland, 9.7\% Italy, 10.0\% UK, $11.0 \%$ Australia and Norway, $12.5 \%$ France, $19.8 \%$ New Zealand, and $20.2 \%$ in the USA. The size of the boxes $(\mathscr{Z})$ is inversely related to the variance of the relative risk. Horizontal lines represent the $95 \%$ CI. 
the labelling of asthma could not totally explain the observed increase. All individuals were interviewed at the same time and although the oldest cohort were twice the age of the youngest, cumulative incidence was lower $(8 \%$ versus $10 \%$, respectively). In addition, sensitivity and specificity of reporting ever asthma against bronchial responsiveness did not change by cohort. Moreover, repeated surveys in children using measures of bronchial responsiveness $[19,20]$ reported an increase similar to those reported by repeated surveys using questionnaire data, although these studies are difficult to interpret because they used instruments which are difficult to standardize. Overall, the nature of the data precludes a definitive answer about the possibilities that some of the findings could be explained by generational increases in asthma diagnosis.

A third limitation in the retrospective approach based on self-reported age of onset of asthma is memory bias. Three types of memory error are common in surveys: telescopic, false negative, and false positive [21]. Telescopic refers to the reporting of the onset of the disease at an older age than that at which it actually occurred, increasing as the time increased. False negative or underestimation has been shown in a prospective study about wheezing [22]. Underestimation increases with time since the condition last occurred and could mimic a generational effect. False positive bias, if it occurs, compensates false negative. The net effect of reporting errors is difficult to predict in the absence of continuous information and the authors could only rely on additional data collected during the crosssectional study. Hence, stratification by the age of onset showed an increase in both childhood and adulthood onset asthma which partially controlled the above errors. In addition, the proportion of active asthma over the cumulative incidence of asthma per cohort reported at the time of interview in 1991-1992 was constant (around $46 \%$ of individuals with asthma). Moreover, the relative risk for females versus males was 0.71 before the age of 15 , and 1.80 afterwards, which agrees with studies using prospective data [23]. These indirect data indicate that recall bias probably does not explain the major part of the present results. A final limitation is nonresponse. Nonresponse varied by age and sex in most of the countries. Although nonresponse was higher in younger ages, the maximum difference by age was $20 \%$ in New Zealand, which could not bias markedly the relative risks, and nonresponse by age did not follow a consistent pattern by age among countries. A sensitivity analyses on the effects of age and sex nonresponse in the prevalence of bronchial responsiveness in the ECRHS indicated that the effect of nonresponse on the estimates is probably minimal [24]. In addition, similar relative risks have been found in countries with low nonresponse, such as Sweden, or high, such as France, suggesting that nonresponse did not significantly bias the findings.

Based on the assumption that these biases did not substantially affect the results, the data suggest the occurrence of a cohort effect, but at the same time are compatible with the possibility that the increase in incidence may be due to a period effect. A cohort effect (i.e., a variation in the health status of each birth cohort in the population independent of the cohorts' age or the time in which they are observed) was suggested by the progressive generational increase in the youngest age group, as well as by the linear increase by cohort in further ages. Studies on trends in asthma mortality have also shown cohort effects in England $[2,9]$ and Australia $[25,26]$, independent of the age and period effects. If these results are interpreted as a cohort effect, the fact that the increase in asthma incidence was already occurring in the earliest cohorts observed (though the change from the first to the second generation was not statistically significant) together with the lack of information on cohorts born before 1945 preclude determining the point in time when the cohort effect started to occur. Nevertheless, the fact that major changes occurred during the period 1961-1965, after which the decline with age in the incidence of asthma was attenuated, coinciding with the highest relative risk for the cohort born between 1961-1965, is compatible with a period effect during the $60 \mathrm{~s}$. The existence of shifts in the time trend during the period 1961-1965 coincides chronologically with an increase in mortality [3-6].

The increase in incidence was observed concurrently in all of the countries, except Norway, the Netherlands, and the USA. This could be a result of chance and increasing prevalence rates of asthma have been reported in Norway $[27,28]$ and the USA [8] during this period. However, there could also be a real heterogeneity. Coinciding with the present data, mortality from asthma in ages 5-34 yrs in the Netherlands declined, rather than increased [29], although many factors other than prevalence may influence mortality. A limitation of the present study is that sample size is too small to allow assessment of the temporal changes at centre level. However, it is important to note that Erfurt (East Germany) showed the lowest generational increase in incidence of all the centres, which coincides with the hypothesis that some environmental differences between the old European East and West are related with asthma inception [30].

The more likely explanation of the generalized increase in prevalence is that for reasons still unknown something has changed that affects incidence. Changes in susceptibility to environmental stimuli leading to asthma $[31,32]$, as well as changes in exposure to environmental factors, such as changes in the load or potency of aeroallergens [33], could have induced this effect. If the increase in asthma incidence is due to a cohort effect, then the explanation which best ties in with the rise of asthma is that this is due to a progressive change in the mode of response to environmental stimuli, determined early in life. Interestingly, the increased incidence by cohort occurred in both those with and without parental asthma, a strong risk factor of asthma inception [34].

The generalized increase in self-reported first asthma attack occurred in the same period in countries with extreme differences in the prevalence of asthma such as the United Kingdom and Spain. This observation is consistent with increased prevalence in repeat surveys in areas with largely differing prevalence rates of asthma [8]. Changes that could explain the increase must be common to all the developed countries. Identification of the point in time when these changes started to occur is limited by the lack of information on cohorts born before 1945. Given the available information, changes could have been occurring in the late 1950s and in the 1960s.

In conclusion, the present analysis has shown how asthma incidence, or alternatively changes in asthma 
diagnosis, has experienced a generalized increase in developed countries during the study period, explaining the observed increase in prevalence.

Acknowledgements. The coordination of this work was supported by the European Commission and the authors are grateful to C. Baya and M. Hallen for their help during the study and to $\mathrm{K}$. Vuylsteek and the members of the COMAC for their support. The following grants helped to fund the local studies: Australia: Allen and Hanbury's, Australia, Belgium: Belgian Science Policy Office, National Fund for Scientific Research; France: Ministere de la Santé, Glaxo France, Insitut Pneumologique d'Aquitaine, Contrat de Plan Etat-Région Languedoc-Rousillon, CNMATS, CNMRT (90MR/10, 91AF/6), Ministre delegué de la santé, RNSP; Germany: GSF, and the Bundesminister für Forschung und Technologie, Bonn, Italy: Ministero del'Universita e della Ricerca Scientifica e Tecnologica, CNR, Regione Veneto grant RSF n. 381/05.93; New Zealand. Asthma Foundation of New Zealand, Lotteries Grant Board, Health Research Council of New Zealand; Norway: Norwegian Research Council project No. 101422/310; Spain: Ministero Sanidad y Consumo FIS grants No. 91/0016060/00E-05E., No. 92/0319, No. 93/0393, Generalitat de Catalunya - CIRIT 1997 GR 00079, Hospital General de Albacete, Hospital General Juan Ramón Jiménez, Consejeria de Sanidad Principado de Asturias; Sweden: The Swedish Medical Research Council, the Swedish Heart Lung Foundation, the Swedish Association against Asthma and Allergy. Switzerland: Swiss National Science Foundation grant 4026-28099; United Kingdom: National Asthma Campaign, British Lung Foundation, Department of Health, South Thames Regional Health Authority; USA: United States Department of Health, Education and Welfare Public Health Service Grant No. 2 S07 RR05521-28.

The principal participants Co-ordinating Centre (London): P. Burney, S. Chinn, C. Luczynska, D. Jarvis, E. Lai. Australia: M. Abramson, J. Kutin (Melbourne); Belgium: P. Vermeire, F. van Bastelaer (Antwerp South, Antwerp Central); France: J. Bousquet (Montpellier) F. Neukirch, R Liard (Paris), I. Pin, C. Pison (Grenoble), A Taytard (Bordeaux); Germany: H. Magnussen, D Nowak (Hamburg); H.E. Wichmann, J. Heinrich (Erfurt); Iceland: T. Gislason D. Gislason (Reykjavik); Ireland: J. Prichard, S. Allwright, D. MacLeod (Dublin); Italy: M. Bugiani, C. Bucca, C. Romano (Turin), R. de Marco, V. Lo Cascio, C. Campello (Verona), A. Marinoni, I. Cerveri, L. Casali (Pavia); Netherlands: B. Rijcken, A Kremer (Groningen, Bergen-op-Zoom, Geleen); New Zealand: J. Crane, S. Lewis (Wellington, Christchurch, Hawkes Bay); Norway: A. Gulsvik, E. Omenaas (Bergen); Spain: J. Antó, J. Sunyer, J. Soriano, A. Tobás, J. Roca, M. Kogevinas (Barcelona), N. Muniozguren, J. Ramos González, A. Capelastegui (Galdakao), J. Martinez-Moratalla, E. Almar (Albacete) J. Maldonado, A. Pereira, J. Sánchez (Huelva), F. Payo, I. Huerta (Oviedo); Sweden: G. Boman, C. Janson, E. Bjornsson (Uppsala), L. Rosenhall, E. Norrman, B. Lundback (Umea), N. Lindholm, P. Plaschke (Goteborg); Switzerland: U. Ackermann-Liebrich, N. Künzli, A. Perruchoud (Basel); United Kingdom: M. Burr, J. Layzqll (Caerphilly), R. Hall (Ipswich), B Harrison (Norwich), J. Stark (Cambridge); USA: S. Buist, W. Vollmer, M. Osborne (Portland)

\section{References}

1. Speizer FE, Doll R. A century of asthma deaths in young people. Br Med J 1967; 3: 245-246.

2. Marks G, Burney P. Diseases of the Respiratory System. In: The Health of Adult Britain 1841-1991, edited by Charlton J, Murphy M. Her Majesty's Stationery Office, London, 1998.

3. Jackson RT, Beaglehole R, Rea HH, Sutherland DC. Mortality from asthma: a new epidemic in New Zealand. Br Med J 1982; 285: 771-774.

4. Burney PGJ. Asthma mortality in England and Wales: evidence for a further increase, 1974-1984. Lancet 1986; 2: $323-326$

5. Bousquet J, Hatton F, Godard P, Michel FB. Asthma mortality in France. J Allergy Clin Immunol 1987; 80: 389394.

6. Jackson R, Sears M, Beaglehole R, Rea H. International trends in asthma mortality. Chest 1988; 94: 914-919.

7. Weiss KB, Gergen PJ, Wagener BK. Breathing better or wheezing worse? The changing epidemiology of asthma morbidity and mortality. Ann Rev Public Health 1993; 14: 491-513.

8. Burr ML. Epidemiology of asthma. In: Epidemiology of clinical allergy. Burr ML, ed. Basel: Karger, 1993, 80102 .

9. Burney PGJ. Asthma deaths in England and Wales 193185: evidence for a true increase in asthma mortality. $J$ Epidemiol Community Health 1988; 42: 316-320.

10. Morrison Smith J. The prevalence of asthma and wheezing in children. Br J Dis Chest 1976; 70: 73-77.

11. Yunginger JW, Reed CE, O'Connell EJ, Melton LJ, $\mathrm{O}^{\prime}$ Fallon WM, Silverstein MD. A community-based study of the Epidemiology of Asthma. Am Rev Respir Dis 1992; 146: 888-894.

12. Burney PGJ, Luczynska P, Chinn S, Jarvis D. The European Community Respiratory Health Survey. Eur Respir J. 1994; 7: 954-960.

13. United Medical and Dental Schools of Guy's and St. Thomas's Hospitals. Protocol for The European Community Respiratory Health Survey. ISBN: 869942019, 1993.

14. Clayton D, Hills M. Statistical models in epidemiology, Oxford University Press, London, 1993.

15. Dickersin K, Berlin JA. Meta analysis: state of the science. Epidemiol Rev 1992; 154-176.

16. Anderson HR, Butland BK, Strachan DR. Trends in prevalence and severity of childhood asthma. Br Med J 1994; 308: 1600-1604.

17. Weltzman M, Gortmaker SL, Sobol AM, Perrin JM. Recent trends in the prevalence and severity of childhood asthma. JAMA 1992; 268: 2673-2677.

18. Samet JM. Epidemiological approaches for the identification of asthma. Chest 1087; 91 (Suppl 6): 74s-78s.

19. Burr ML, Butlan BK, King S, Vaughan-Williams E. Changes in asthma prevalence: two surveys 15 years apart. Arch Dis Child 1989; 64: 1452-1456.

20. Peat JK, van der Berg RH, Green WF, Mellis CM, Leeder SR, Woolcock AL. Changing prevalence of asthma in Australian children. Br Med J 1994; 308: 1591-1596.

21. Stewart W, Brookmayer R, Van Natta MV. Estimating age incidence from survey data with adjustments for recall errors. J Clin Epidemiol 1989; 42: 869-875.

22. Strachan DP, Butland BK, Anderson HR. Incidence and prognosis of asthma and wheezing illness from early childhood to age 33 in a national British cohort. $B M J$ 1996; 312: 1195-1199. 
23. Readline $\mathrm{S}$. Challenges in interpreting gender differences in asthma. Am J Respir Crit Care Med 1994; 150: 1219-1221.

24. Chinn S, Burney P, Jarvis D, Luczinska C, on behalf of the ECRHS. Variation in bronchial responsiveness in the European Community Respiratory Health Survey. (ECRHS). Eur Respir J 1998; 10: 2495-2501.

25. Bauman A, Lee S. Trends in asthma mortality in Australia, 1911-1986. Med J Aust 1990; 153: 366-367.

26. Taylor R, Comino E, Bauman A. Asthma mortality in Australia 1920-94: age, period, and cohort effects. $J$ Epidemiol Community Health 1997; 51: 408-411.

27. Magnus P, Kongerud J, Bakke W. Har vi en astmaepidemi? Tidsskr Nor Lageforen 1991; 111: 972-975.

28. Skjnsberg O, Clench-Aas J, Leegaard J, et al. Prevalence of bronchial asthma in schoolchildren in Oslo, Norway. Comparison of data obtained in 1993 and 1981. Allergy 1995; 50: 806-810.
29. Wever-Hess J, Wever AM. Asthma statistics in The Netherlands 1980-94. Respir Med 1997; 91: 417-422.

30. Von Mutius E, Fritsch C, Weiland SK, Roll G, Magnusen $\mathrm{H}$. Prevalence of asthma and allergic disorders among children in united Germany: a descriptive comparison. BMJ 1992; 305: 1395-1399.

31. Shaheen SO. Changing patterns of childhood infection and the rise in allergic disease. Clinical Experimental Allergy 1995; 25: 1034-1037.

32. Seaton A, Godden DJ, Brown K. Increase in asthma: a more toxic environment or a more susceptible population?. Thorax 1994: 49: 171-174.

33. Burr ML. Is asthma increasing? J Epidemiol Com Health 1987; 41: 185-189.

34. Sherman CB, Tosteson TD, Tager IB, Speizer FE, Weiss ST. Early childhood predictors of asthma. Am J Epidemiol 1990; 132: 83-95. 